\title{
Physical, technological and technical characteristics of the blasted rock mass in terms of energy intensity of the processes
}

\author{
Ivan Panachev $^{1 *}$, Ilya Kuznetsov ${ }^{1}$, and Anastasia Shirokolobova ${ }^{1}$ \\ ${ }^{1}$ T.F. Gorbachev Kuzbass State Technical University, 28 Vesennya St., Kemerovo, 650000, \\ the Russian Federation
}

\begin{abstract}
Kuzbass coal mines are equipped with powerful mining equipment; it is CME excavator type with bucket capacity from $4.6 \mathrm{~m}^{3}$ to $20 \mathrm{~m}^{3}$. To evaluate the efficiency of the excavation processes, a universal criterion was used - the value of specific energy consumption $\left(\mathrm{kW} \mathrm{h} / \mathrm{m}^{3}\right)$. The dependences of excavator efficiency on the quality of rock blasting, estimated by the diameter of the average piece in the shot pile, are obtained. The relationship between the efficiency of excavators CME - 4.6, $\mathrm{CME}-8, \mathrm{CME}-12.5, \mathrm{CME}-20$, their energy intensity and the diameter of an average piece in the shot pile is determined.
\end{abstract}

The total energy consumption per cycle, referred to the volume of the loaded rock mass, characterizes the physical, technical and technological parameters of the face, and is the main indicator that determines the efficiency of excavation and transportation processes.

The quality of the face preparation can be estimated by the energy intensity of the excavation process. The most acceptable energetic and technological parameter is the specific energy consumption, which depends on a number of technological indicators - the coefficient of scarification of the rock in the shot pile, the coefficient of filling of the excavator bucket, its capacity, efficiency, duration of operation and rated power.

Theoretical assessment of energy consumption was carried out according to the formula (1)

$$
E_{S}=\frac{K_{m} K_{s} c\left(K_{l} P_{n} t_{n} \frac{1}{\eta_{n}}+K_{l} P_{v} t_{v} \frac{1}{\eta_{v}}\right)}{K_{f} C},
$$

where $E_{\mathrm{s}}-$ specific energy consumption, $\mathrm{kW} \cdot \mathrm{h} / \mathrm{m} 3 ; \mathrm{K}_{\mathrm{m}}$ - coefficient taking into account the energy consumption for manoeuvres, face preparation and auxiliary works; $\mathrm{K}_{\mathrm{s}}$ coefficient of scarification of the rock in the excavator bucket; $\mathrm{c}$ - coefficient taking into account the total energy consumption; $\mathrm{K}_{\mathrm{f}}$ - filling factor of the bucket with scarified rock; $\mathrm{C}-$ is the bucket capacity, $\mathrm{m}^{3} ; \mathrm{K}_{1}$ - loading factor; $\mathrm{P}_{\mathrm{n}}-$ nominal capacity, $\mathrm{kWe} ; \eta_{n}-$

\footnotetext{
${ }^{*}$ Corresponding author: pia.sm@kuzstu.ru
} 
efficiency factor; $t_{n}$ - the duration of the work during the cycle of the thrusting engine, $\mathrm{h}$; $K_{l .}, P_{v}, \eta_{v}, t_{v}$ - loading factor, nominal capacity, efficiency factor and operating time during the cycle of the rotary engine, respectively.

However, a theoretical assessment of energy consumption is associated with significant difficulties. The components of the excavation cycle $\left(t_{n}, t_{v}\right)$ and the coefficients are set according to the type of an excavator, the quality of the preparation of the face and the developed stope.

In Kuzbass open pits loading upward digging shovels are the most widely used for the development of blasted rock. Their effectiveness is determined by both the quality of the rocks preparation for excavation and their design parameters that evaluate their efficiency, which is the most important indicator of their effectiveness in the mining and energy intensity of the excavation process.

The efficiency indicators of the excavation process are quantitative assessment of the constructive capabilities of the excavator in specific operating conditions, which take into account the properties of the rock mass described by the diameter of the natural separation $d_{e}$, the diameter of the average piece in the shot pile after the explosion, the scarification coefficient, the excavation coefficient, and the cycle duration [1].

The quality of preparation for explosions for excavation depends on the fracturing of the rock, the parameters of drilling and blasting operations - the diameter of the blasted wells, the specific consumption of explosives and other indicators that affect the efficiency of explosive crushing.

To assess the quality of rock preparation by an explosion, the diameter of the middle piece in the collapse, determined by the formula, was used. To assess the quality of rock preparation by an explosion, the diameter of the average piece in the shot pile, determined by the formula, was used

To assess the quality of rock preparation by an explosion, the diameter of the average piece in the shot pile, determined by the formula, was used

$$
d_{a p}=\frac{1}{\frac{0.4}{\bar{c}}+\frac{300+h}{100+d_{c}} q},
$$

where $h$ is the cutting depth, $\mathrm{m} ; \bar{c}$ is the average power of the rock sheet composing the bench, $\mathrm{m} ; q$ - specific consumption of explosives, $\mathrm{kg} / \mathrm{m}^{3} ; d_{\mathrm{c}}$ is the diameter of the well charge, $\mathrm{m}$

And the coefficient of scarification, determined by the formula from the expression

$$
k_{s}=0.5 q\left(d_{e}+q\right)^{-1}+1
$$

where $d_{e}$ - is a diameter of natural separation, $m$.

An important mining characteristic is its fracturing, which determines the quality of explosive preparation of rocks for excavation.

At the same time, the quality of rock preparation by an explosion substantially depends on technological factors: the development system, the specific explosive consumption, the design of explosive charges, and short-delay blasting schemes.

The main factors determining the efficiency of mining equipment are the diameter of the average piece in the shot pile, the excavation coefficient and cycle time.

As an indicator of the efficiency of the excavation process, the coefficient is taken

$$
k_{e}=\frac{Q_{m}}{Q_{o}}
$$


where $Q_{m}$ - excavator technical efficiency; $Q_{o}$ - excavator passport efficiency.

This value is a quantitative assessment of the implementation of the design capabilities of the excavator.

Excavator efficiency is functionally related to the duration of the working cycle and the values of the excavation coefficient, depending on the type of adopted technology and determining the efficiency of using the bucket geometric capacity

$$
K_{e}=0.83 \exp \left(-2 \frac{d_{a p}^{5}}{c^{0.2}}\right),
$$

where $d_{a p}$ - the diameter of an average piece in shot pile, $\mathrm{m}$; $\mathrm{C}$ - excavator bucket capacity.

To assess the impact of auxiliary operations on excavator efficiency (CME), the technology impact coefficient was used, determined by the formula

$$
K_{t i}=\exp \left(-0.45 \frac{d_{a p}^{2}}{c^{0.5}}\right)
$$

Cycle time was determined

$$
t_{c}=t_{\text {filling }}+t_{\text {raise }}+t_{\text {installation }}+t_{\text {descent }}+t_{\text {discharge }}
$$

were $t_{\text {discharge }} \approx 2.6 \sqrt[3]{E}$.

The scarification of the blasted rock mass is characterized by the diameter of the average piece in the shot pile, which significantly affects the parameters of the excavation process the bucket filling factor, scarification coefficient, digging time and cycle time, which determines the operational efficiency of excavators.

$$
Q_{e}=\frac{3600 E}{t_{u}} K_{b f} K_{b d} t_{c} t_{c}
$$

where $K_{b f}$ - bucket filling factor; $K_{b d}$ - bucket discharge factor; $t_{c}$ - crowding action factor; $t_{c}$ - cycle time.

Thus, the quality of the rocks preparation with cyclic-flow technology significantly determines the efficiency of mining equipment.

Figure 2 graphically shows the distribution of excavator output per shift - mechanical shovel CME-4.6; CME - 8; CME - 12.5; CME-20 at various values of the diameter of the average piece in the shot pile. 


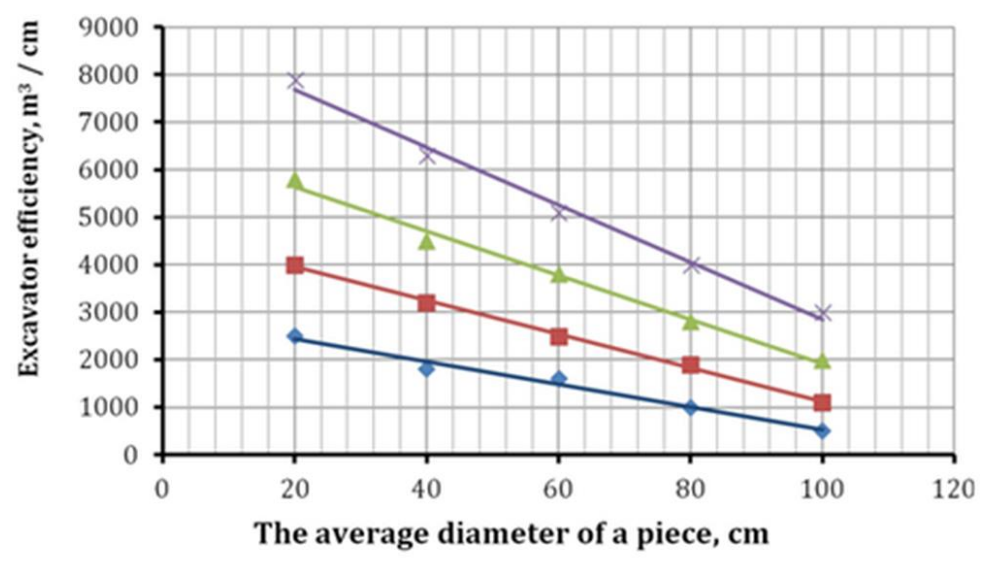

- CME-4.6 CME-8 $\triangle$ CME-12.5 $\times$ CME-20

Fig. 1. Dependence of excavator efficiency on the diameter of an average piece in the face

As a result of obtained graphs processing, a functional relationship between the average piece diameter in the shot pile and the efficiency of an excavator was established (Table 1).

Table 1. Functional dependencies of various models of excavators

\begin{tabular}{|c|c|c|}
\hline Excavator & Functional dependences & $\begin{array}{c}\text { Determination } \\
\text { coefficient }\end{array}$ \\
\hline CME-4.6 & $\mathrm{Q}=-24 \mathrm{~d}_{\mathrm{ap}}+2920$ & 0.9813 \\
\hline $\mathrm{CME}-8$ & $\mathrm{Q}=-35.5 \mathrm{~d}_{\mathrm{ap}}+4670$ & 0.9978 \\
\hline $\mathrm{CME}-12.5$ & $\mathrm{Q}=-46.5 \mathrm{~d}_{\mathrm{ap}}+6570$ & 0.9909 \\
\hline $\mathrm{CME}-20$ & $\mathrm{Q}=-60.5 \mathrm{~d}_{\mathrm{ap}}+8890$ & 0.9911 \\
\hline
\end{tabular}

Figure 1 shows that the efficiency of excavators decreases significantly with an increase of the average piece in the shot pile, which characterizes the granulometric composition of the blasted rock mass.

The classification of I. Tangaev is taken for the basis of estimation of energy intensity of the loading of rock mass, it takes into account the quality of scarification, shot pile height, entry number, working out of the bottom of the face, removal of oversize and other indicators.

Excavation specific energy costs

$$
\begin{aligned}
& W=\frac{E}{Q_{\text {tech. }}}=\frac{E}{Q_{e}} . \\
& Q_{\text {mex. }}=\frac{3600 E}{T_{c .} .} k_{e} k_{f},
\end{aligned}
$$


where $Q_{e}$ - operational efficiency; $E$ - bucket volume, $\mathrm{m}^{3} ; T_{c . d}$. cycle duration, $\mathrm{c} ; k_{e}-$ excavation coefficient; $k_{f}$ - face coefficient taking into account the influence of auxiliary operations.

Cycle duration

$$
T_{\text {c.d. }}=t_{\text {filling }}+t_{\text {raise }}+t_{\text {installation }}+t_{\text {descent }}+t_{\text {discharge }} .
$$

The efficiency of the excavation process in the blasted rock development is assessed by the quality of the rock preparation and the constructive capabilities of the excavators. Excavation parameters are determined by the quality of preparation of the face, characterized by the average diameter of the piece in the shot pile and the coefficient of scarification of the rock in the shot pile and the technological parameters of the excavator the capacity of the bucket. The efficiency index of the excavation process, which is a quantitative assessment of the design capabilities of the excavator, is determined by the ratio of the technical productivity of the excavator to the passport

$$
k_{e}=Q_{t} /_{Q_{o}}
$$

As a result of studies performed in the Kuzbass open pits, the excavation coefficient is determined from the expression:

$$
k_{e}=0.83 \exp \left(-2 \frac{d_{a p}^{5}}{E^{0.2}}\right)
$$

The energy intensity of excavation depends on the physical and technical parameters of the face - the scarification coefficient, the quality of the explosive preparation of rocks for excavation, the height and width of the shot pile of the blasted rock, the quality of the work out of the bottom, face, angle of rotation of the excavator during loading and other auxiliary operations.

Tangaev I.A. proposed the energy scale for the excavation of rocks in faces with various mining and geological conditions and physical and technological properties; it is recommended for practical use, which takes into account the category of excavation of rocks, specific energy consumption of rock loading and excavator efficiency.

Table 2. The scale of crushing levels according to I. A. Tangaev

\begin{tabular}{|c|c|c|}
\hline $\begin{array}{c}\text { Qualitative level of face } \\
\text { preparation }\end{array}$ & $\begin{array}{c}\text { Excavation energy intensity, } \\
\mathbf{k W} \mathbf{h} / \mathbf{m}^{\mathbf{3}}\end{array}$ & Probable values $\boldsymbol{d}_{\boldsymbol{a p}}, \mathbf{m m}$ \\
\hline Good & $<0.4$ & $<200$ \\
\hline Satisfactory & $0.4-0.7$ & $<300$ \\
\hline Bad & $0.7-0.9$ & $<400$ \\
\hline Very bad & $>0.9$ & $>400$ \\
\hline
\end{tabular}

The energy scale of excavation of rocks in the conditions of coal mines in Kuzbass was built (Table 3): 
Table 3. The scale of rock excavation

\begin{tabular}{|c|c|c|c|c|c|c|}
\hline \multirow{2}{*}{\multicolumn{2}{|c|}{$\begin{array}{l}\text { Category of } \\
\text { Rock } \\
\text { Excavation }\end{array}$}} & \multirow{2}{*}{$\begin{array}{c}\text { Specific energy } \\
\text { intensity of loading } 1 \\
\mathbf{m}^{3} \text { of rock mass, } \mathbf{k W} * \\
\qquad \mathbf{h} \backslash \mathrm{m}^{3}\end{array}$} & \multicolumn{4}{|c|}{ Excavator output per shift, $\mathrm{m}^{3} / \mathrm{cm}$} \\
\hline & & & CME-4.6 & CME-8 & CME-12.5 & $\begin{array}{c}\text { CME- } \\
20\end{array}$ \\
\hline $\mathrm{I}$ & 0.5 & $0.16-0.24$ & \multirow{2}{*}{2000} & \multirow{2}{*}{2300} & \multirow{2}{*}{2400} & \multirow{2}{*}{2700} \\
\hline II & 1.0 & $0.24-0.32$ & & & & \\
\hline III & 1.5 & $0.32-0.44$ & \multirow{2}{*}{1800} & \multirow{2}{*}{2200} & \multirow{2}{*}{2300} & \multirow{2}{*}{2700} \\
\hline IV & 3 & $0.44-0.56$ & & & & \\
\hline $\mathrm{V}$ & 4 & $0.56-0.72$ & \multirow[t]{2}{*}{1600} & \multirow[t]{2}{*}{2100} & \multirow[t]{2}{*}{2200} & \multirow[t]{2}{*}{2700} \\
\hline VI & 6 & $0.72-0.92$ & & & & \\
\hline VII & 8 & $0.92-1.2$ & 1300 & 2000 & 2100 & 2500 \\
\hline VIII & 10 & $>1.2$ & $<1000$ & $<2000$ & $<2100$ & $<2500$ \\
\hline
\end{tabular}

Excavation parameters during the development of blasted rock are determined by the quality of the face preparation (the diameter of the average piece in the shot pile and the coefficient of scarification of the rock) and the technological parameters of the excavator (bucket capacity C). If these indicators are not enough for a full assessment, the specific resistance to digging is introduced into the calculations, the influence of oversized fractions, etc.

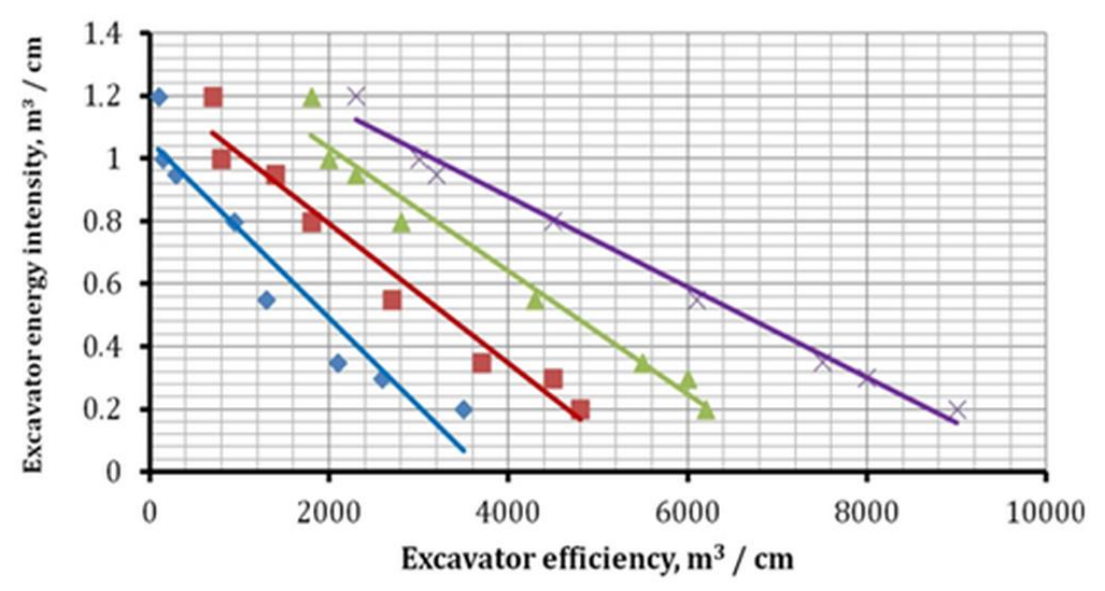

- CME-4.6 $=$ CME-8 $\triangle$ CME-12.5 $\times$ CME-20

Fig. 2. The dependence of the excavator energy intensity on its efficiency

As a result of obtained graphs processing, functional dependencies were established between the efficiency of excavators and the energy intensity of the excavation process (Table 4). 
Table 4. Functional dependencies of various models of excavators

\begin{tabular}{|c|c|c|}
\hline Excavator & Functional dependence & $\begin{array}{c}\text { Determination } \\
\text { coefficient }\end{array}$ \\
\hline $\mathrm{CME}-4.6$ & $\mathrm{E}_{\mathrm{s}}=-0.0003 \mathrm{Q}+1.0573$ & 0.9161 \\
\hline $\mathrm{CME}-8$ & $\mathrm{E}_{\mathrm{s}}=-0.0002 \mathrm{Q}+1.2373$ & 0.9624 \\
\hline $\mathrm{CME}-12.5$ & $\mathrm{E}_{\mathrm{s}}=-0.0002 \mathrm{Q}+1.4268$ & 0.9713 \\
\hline $\mathrm{CME}-20$ & $\mathrm{E}_{\mathrm{s}}=-0.0001 \mathrm{Q}+1.4545$ & 0.9882 \\
\hline
\end{tabular}

Figure 2 shows the dependences of the output per shift of excavators on the energy intensity of excavation of blasted rocks, which are described by the empirical dependencies of the parabolic type with correlation coefficients:

$C M E-4.6-R^{2} \approx 0.97$; CME $-12.5 \approx 0.97$; CME $-20 \approx 0.99$, which characterizes a high stable relationship of the studied parameters.

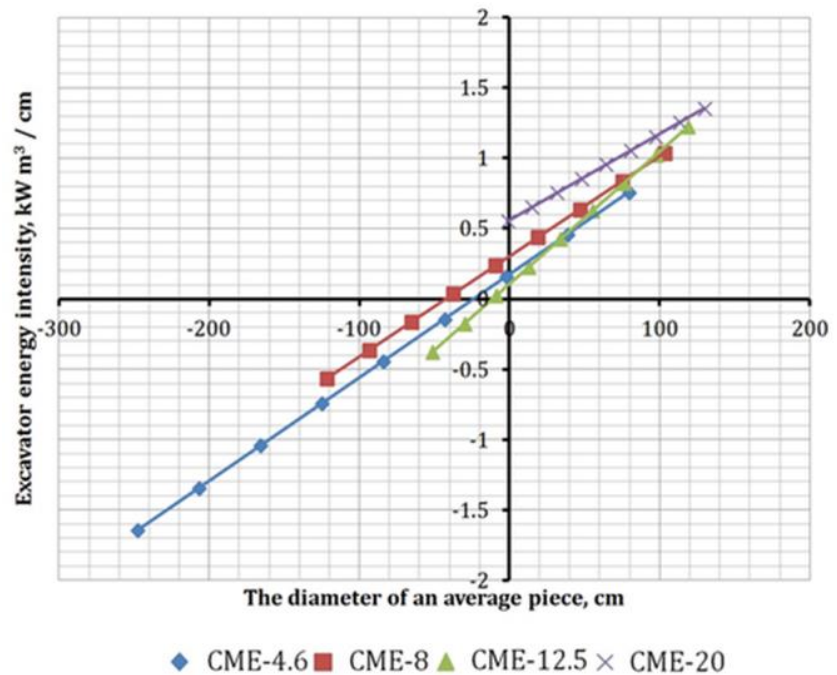

Fig. 3. The dependence of the energy intensity of excavation on the diameter of an average piece in the shot pile

Table 5 shows the empirical dependencies of the energy intensity of the considered excavator models. 
Table 5. Functional dependencies of various models of excavators

\begin{tabular}{|c|c|}
\hline Excavator & Functional dependences \\
\hline CME- 4.6 & $\mathrm{E}_{\mathrm{s}}=0.0073 \mathrm{~d}_{\mathrm{ap}}+0.1734$ \\
\hline CME -8 & $\mathrm{E}_{\mathrm{s}}=0.0071 \mathrm{~d}_{\mathrm{ap}}+0.3021$ \\
\hline CME -12.5 & $\mathrm{E}_{\mathrm{s}}=0.0094 \mathrm{~d}_{\mathrm{ap}}+0.1071$ \\
\hline $\mathrm{CME}-20$ & $\mathrm{E}_{\mathrm{s}}=0.0061 \mathrm{~d}_{\mathrm{ap}}+0.5632$ \\
\hline
\end{tabular}

The dependencies in figure 4 were obtained analytically by comparing the functional equations presented in tables 1 and 4. Taking into account the physical basis of the processes under study, the lines located in quarters II, III, and IV should be excluded.

The graphs of the first quarter are straight lines corresponding to the linear distribution law. The trend line of experimental points for CME excavators - 12.5 has intersections with all trend lines for other models. This indicates that the operation of the CME -12.5 excavator in certain ranges of the face of the mine preparation turns out to be more efficient according to the energy intensity criterion in comparison with other types of excavators under consideration. Thus, we can conclude that the CME -12.5 loader is more versatile in terms of the functional relationship "form factor - bucket capacity - power".

A common pattern for mechanical shovels is an increase in specific energy consumption with a decrease in bucket volume, if the parameters of their electric drives are similar and the efficiency of the loading machines will correspond to the size of the diameter of the average piece of 0.2-0.4 m.

\section{References}

1. I. A. Tangaev, Energy Intensity of mining and processing of minerals (Nedra, Moscow, 1986)

2. N. Ya. Repin, Preparation and excavation of overburden rocks of coal sections (Nedra, Moscow, 1978)

3. I. A. Panachev, Assessment of the quality of preparation of the face for excavation according to the energy intensity of processes (Proceedings of the III international scientific-practical conference "high-Tech technologies of mining and processing of minerals", Novosibirsk, 2003)

4. N. Ya. Repin., A.V. Biryukov and A. S. Tashkinov, Technological properties of coalcut rocks (Kospi , Kemerovo, 1975)

5. I. A. Panachev, A.V. Biryukov, Mining journal, 2, 64-66 (1986)

6. N. Y. Repin, V. P. Bogatyrev, V. D. Butkin, A. S. Tashkin, Drilling and blasting operations at coal mines (Nedra, Moscow, 1987) 
7. B. N. Kutuzov, Design and organization of blasting operations: The Textbook (Publishing house."Mountain book", Moscow, 2012)

8. M. N. Cook, Science of industrial explosives (Nedra, Moscow, 1986)

9. K. Hino, Journal of the Industrial Explosives Society, Japan, 18: 4 (1957)

10. T. Sakurai, Journal of the industry, Japan, 20: 1 (1959)

11. J. M. Walsh and R. H. Christian, Phys, 97 (1954)

12. R. Raspet. P. Butler. F. Yahani, Appl. Acoust, 22: 3, 243-259 (1987)

13. R. Raspet, S. Griffists, J. Acoust. Soc. Amer., 74: 6, 1757-1763 (1983)

14. T. D. Panezak, P. B. Butler, H. Krier, J. Haz. Mater, 14: 4, 321-336 (1987)

15. J. Rowers, H. Krier, J. Haz. Mater, 13: 1, 121-133 (1987)

16. I. B. Katanov, I. S. Fedotenko, Low-Density materials in the construction of borehole charges at quarries (Kuzbassvuzizdat,, Kemerovo,2012)

17. V. N. Lyubimov, A. I. Skushnikova, Safety in the technosphere, 4, 55-58 (2014)

18. Federal rules and regulations in the field of industrial safety "safety Rules for blasting". Approved by Rostekhnadzor Order № 605 of 16.12.2013 (Publishing house "Ural Yur Izdat", Ekaterinburg, 2014) 